
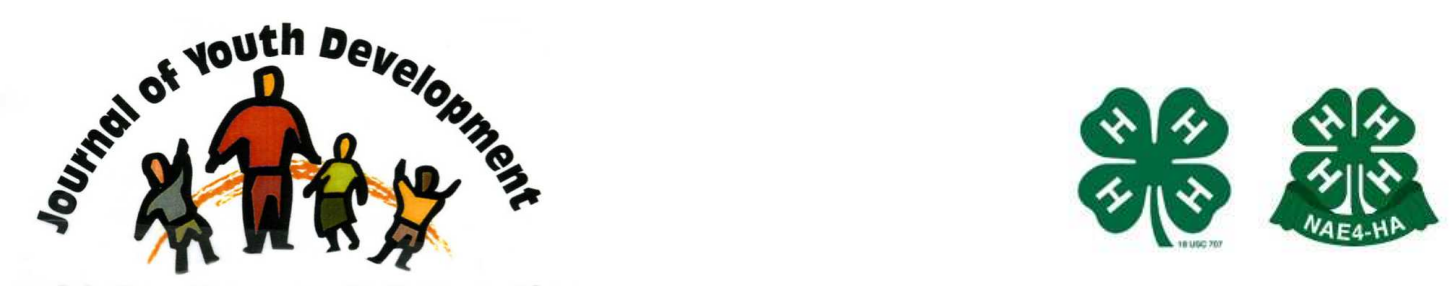

Bridging Research \& Practice

\title{
Mapping Out Your Success: Using Mind Maps to Evaluate Youth Development Programs
}

Mary Sara Wells

University of Utah

Salt Lake City, UT

mary.wells@hsc.utah.edu

Skye G. Arthur-Banning

Clemson University

Clemson, SC

sarthur@clemson.edu 


\title{
JOURNAL OF YOUTH DEVELOPMENT \\ bridging research and practice

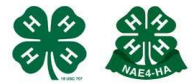

Volume 4, Number 2, Summer 2009

Article 090402RS001

\section{Mapping Out Your Success: \\ Using Mind Maps to Evaluate Youth Development Programs}

\author{
Mary Sara Wells \\ University of Utah
}

Skye G. Arthur-Banning

Clemson University

\begin{abstract}
A primary component of any youth program is documenting and promoting the results through evaluation. Frequently, however, administrators in youth development programs struggle to find meaningful ways of evaluating the impacts they have on the lives of youth. It is often difficult to capture the unique benefits these programs offer to participants, especially when traditional methods such as focus groups and interviews may be too time consuming and questionnaires may yield poor response rates. This article presents a creative form of evaluation targeted at demonstrating the success of programs in outcomes that are historically more difficult to measure. A "mind map" is designed to be a pictorial representation of the impact of programs in areas such as connections to community organization and adult role models. Employing this technique can enable administrators in youth development programs to demonstrate to stakeholders the benefits they provide in a non-traditional, but highly effective, way.
\end{abstract}

\section{Introduction}

\section{Evaluation in Youth Programs}

The importance of evaluation in youth programs cannot be underestimated. In fact, it is a critical part of the entire programming cycle for any program (DeGraaf, Jordan, \& DeGraaf, 1999). It is through evaluation that administrators are able to find ways of improving their services, determine areas that are ineffective, and assess their goals and objectives. Evaluation can also help them to improve decision making, justify expenditures and accountability, communicate successes to stakeholders, and comply with external regulations (DeGraaf et al., 1999; Henderson \& Bialeschki, 2002). 
While evaluation has always been an important component of youth programs, it is perhaps, even more crucial in the current era of limited and competitive funding. Reduced internal funding has necessitated most youth serving agencies to seek outside sources of funding from foundations and other granting agencies. Funds from these organizations almost always require that an evaluation component be adequately described in the grant application and future funding is often contingent on the results of these evaluations. In essence, funding agencies want to know that their funds are being used wisely and effectively (Caldwell et al., 2008).

Many youth program administrators, however, may struggle with this particular aspect of managing youth services for a variety of reasons. Those without a background in evaluation may find the process overwhelming, may find it difficult to collect reliable data (Bocarro, Greenwood \& Henderson, 2008) or may find themselves needing to hire external evaluators. Unfortunately, this is often difficult in already tight budgets. Those who do have evaluation experience may still struggle with the evaluation process due to limited budgets, personal or program time constraints or staffing issues. All of these factors may lead to significant difficultly in conducting focus groups or interviews or poor response rates from questionnaires.

Furthermore, several of the important benefits young participants gain from these types of programs are more difficult to quantify in typical evaluation formats. Consequently, even when the evaluations are done well, there is a concern that they are not reflective of all the benefits youth receive from participation (Gilliam \& Zigler, 2000; Witt \& Crompton, 1999). For example, the Search Institute's 2004 list of 40 developmental assets provides an inventory of specific building blocks that are critical to positive youth development. Among these, are several which are difficult to measure such as a caring neighborhood, other adult relationships, youth as resources, and positive peer influences. Youth serving agencies designed around improving these areas may find it difficult to demonstrate their impact on the lives of youth simply due to a lack of adequate measurement tools. Based on all these difficulties, it becomes apparent that new and unique evaluation methods would be tremendously beneficial in helping youth serving agencies to publicize their benefits to stakeholders and meet the requirements of current and future funding opportunities.

\section{Mind Maps as Evaluation Tools}

One potential evaluation method that might be utilized in these cases is a "mind map." The mind map is a pictorial representation of connections that have been developed as the result of a particular program. It has been successfully used in community serving programs and could be similarly applied in youth serving agencies (Wells \& Arthur-Banning, 2007). So far, when the mind map has been used by the authors, funding agencies and other stakeholders such as boards of directors and community partners have been highly receptive. In fact, some stakeholders have stated that this form of evaluation has helped them more clearly present and explain the impact and sustainability of their programs (Sharon Lone, personal communication, February 10, 2009). The validity of this form of evaluation can be determined much in the same way as through any type of qualitative analysis. In particular, it would be useful for at least two individuals to go through the mind map independently to help ensure objectivity when reporting the number and strength of the relationships and connections listed (Cresswell, 1998).

Essentially, the mind map records the relationships that exist as a result of program participation in year one. In subsequent years, a new map is created using the existing map as a base from which to expand and once the years are compiled; a visual representation exists of the changes that have occurred from year to year. A series of mind maps from one year to the 
next not only assist the agencies in highlighting their program effectiveness, but allows various stakeholders to see just how far reaching and interconnected their programs have the potential to be.

As an example, if an agency (Carson's Kids) begins accepting children into their program, the relationships that currently exist when the program begins would represent the baseline (see Figure 1).

Figure 1

Baseline Carson's Kids Example

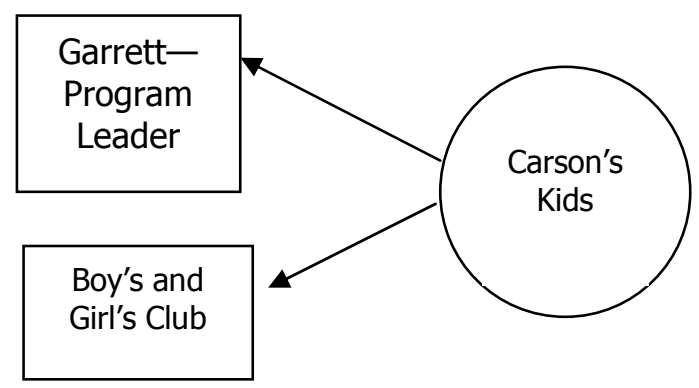

In this example, the youth in the program take part in activities at the local Boy's and Girl's club and they have a leader (Garrett) who can be seen as a positive adult role model. During the course of the year, the participants in Carson's Kids continue to build relationships and are introduced to new activities. The director of the group can record these changes as they occur and at the end of the year it is clear what has taken place (see Figure 2).

Figure 2

End of Year 1 Carson's Kids Example

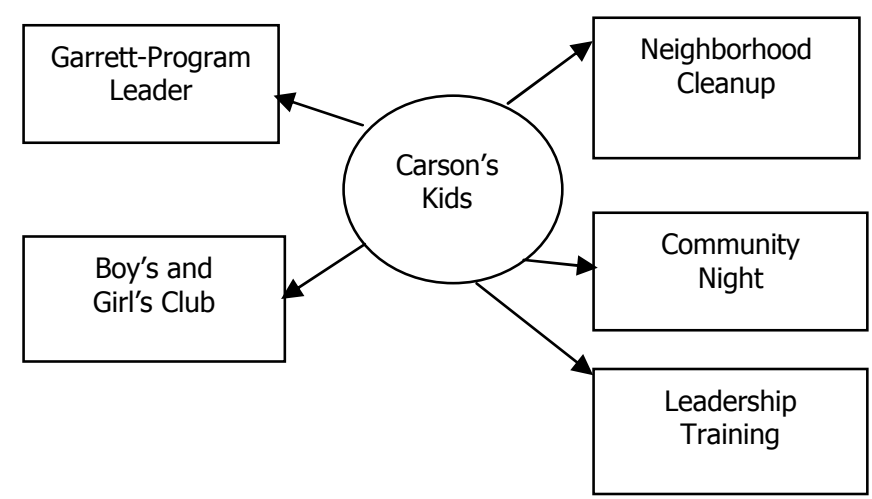


In this instance, the youth in this hypothetical program have added to their experience in the Boy's and Girl's Club by taking part in a neighborhood park clean-up (Youth as Resources), hosting a community night at the center (Caring Neighborhood), and beginning a leadership training program (Positive Peer Influences).

This process could continue for future years (see Figure 3), in which, for example, children in the program continue their current opportunities, but add additional ones such as an adult mentoring program (Adult Relationships) and youth teaching new members through the leadership program (Youth as a Resource and Positive Peer Influences). Furthermore, the community night at the center could lead to involvement of more involvement of volunteers in the after-school homework program (Adult Relationships and Caring Community) and the Neighborhood Cleanup might get recognized with an award from Community Leaders (Caring Community).

Figure 3

End of Year 2 Carson's Kids Example

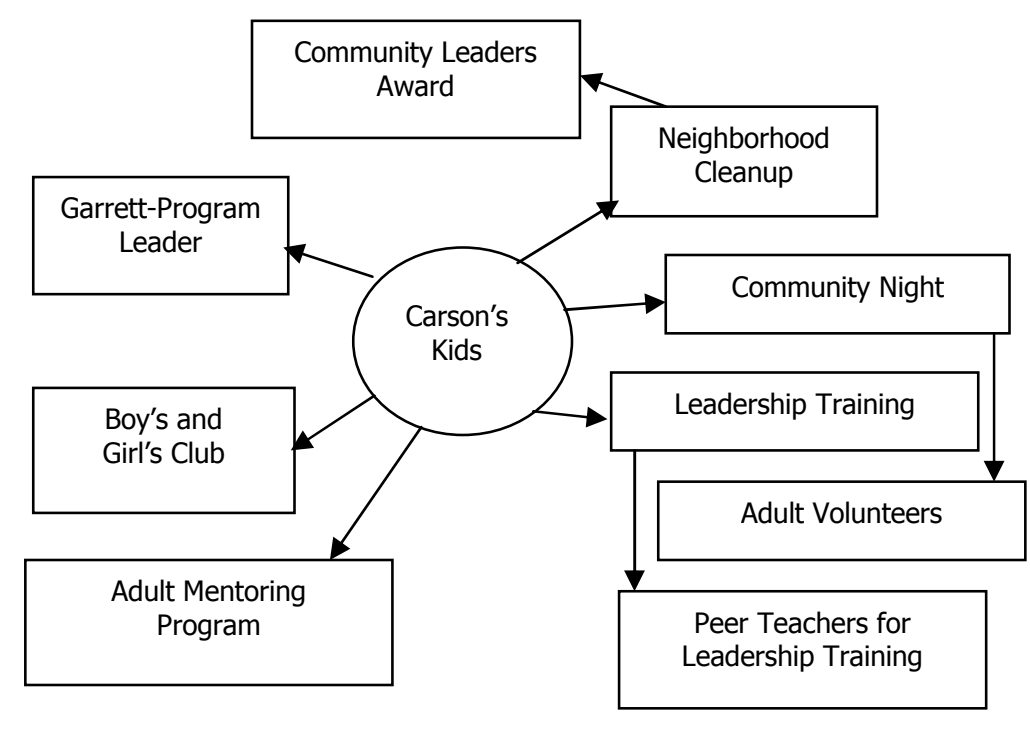

Together, these mind maps capture some of the more difficult assets to measure in a typical assessment. In this example, it is clear that following two years in the program, Carson's Kids has helped participants increase their relationships with non-parent adults, has demonstrated that the community cares and is connected to the youth in the program, has provided positive peer role models for younger participants, and has proven to the youth that they can be a resource for change. Consequently, stakeholders will be able to instantly recognize the contribution of the program on several of the developmental assets, thereby demonstrating the effectiveness of the program on positive youth development. It might also be beneficial to color code these connections or to provide a brief narrative at the bottom to make it even more apparent which of the developmental assets or other goals have been met (see Figure 4). 
Figure 4

End of Year 2 Carson's Kids Example - Color Coded

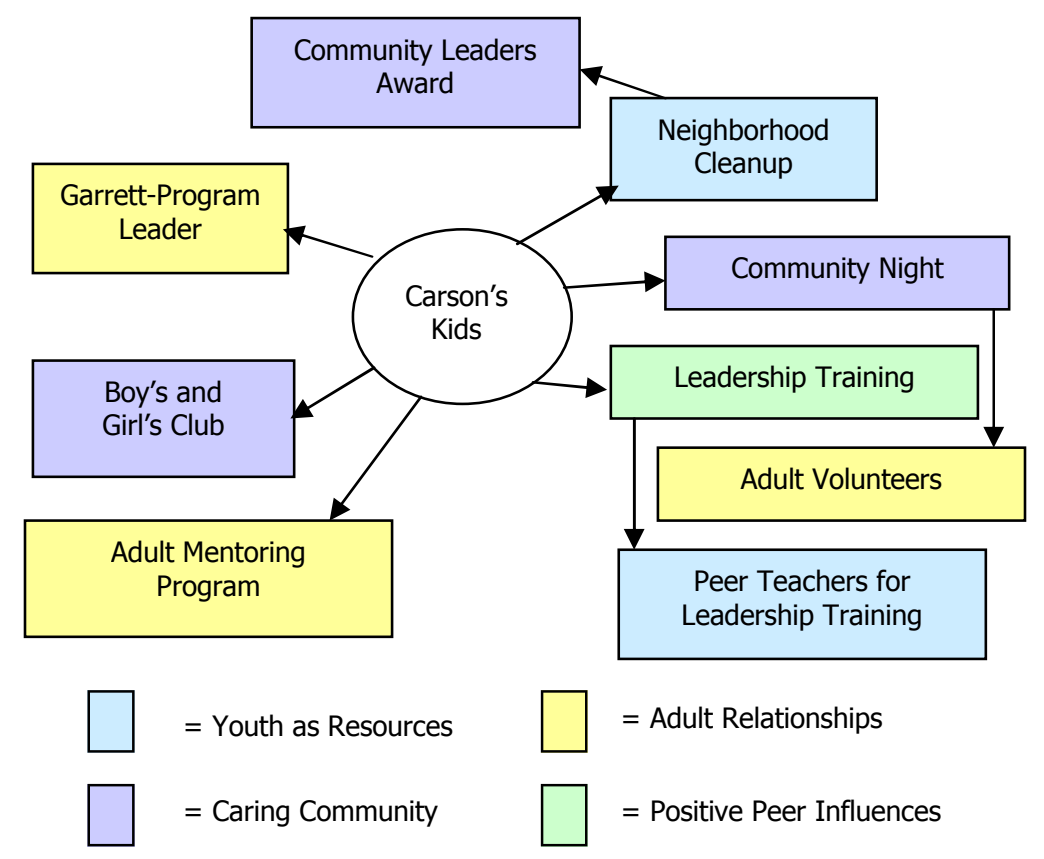

Using a mind map has several clear benefits. To begin with, once it has initially been constructed, it is relatively inexpensive and requires little time to continue from year to year. As new connections are created or old ones are dissolved, it will simply take minutes to adapt the model. In addition, the pictorial representation of the changes that have occurred within an agency during a year provides stakeholders and funding agencies with a clear and concise picture of what a particular organization has accomplished and why it should continue to receive funding. This is perhaps the most important benefit for both administrators and participants as it will help valuable programs to continue serving the lives of youth.

While youth serving agencies continue to struggle with how to best conduct the evaluations that are necessary for their programs without compromising services, new and unique methods of data collection and analysis must be used that are inexpensive, not time consuming, and that accurately represent the multitude of benefits young participants receive as a result of their programs. The mind map is one example of how creative techniques can be effectively used to both gather information and promote successes to stakeholders.

\section{Recommendations}

In addition to serving as an evaluation tool, the mind map may also serve other purposes within an organization. In particular, the mind map could help youth serving agencies to maintain a focus on their missions. Many times opportunities are presented to make connections with partners that may or may not be the best fit for agencies. By mapping out the potential relationship it might be easier for administrators to quickly see how these relationships fit within the realm of their mission and can then determine whether it would be an appropriate use of their time and resources. Similarly, administrators may note when completing their mind map that relationships or connections are missing in certain areas that are key to their mission. This 
would provide them guidance on areas where they should seek out connections that would further their service to participants.

Although the mind map can be a useful tool for evaluation, there remain some issues that need to be addressed. More research should be conducted to confirm its efficacy and usefulness. This might include determining the venues in which the mind map would be most beneficial and those venues in which other forms of evaluation may be more appropriate. Evaluators of youth programs should also be careful to remember that it is only one method of presenting data. Mind Maps should not be used to completely replace current methods of evaluation which are effective in reporting program results. Instead, it is a tool that is meant to enhance these methods in order to give a more complete picture of the program and its successes, particularly those that are more difficult to enumerate. Through the information provided in the mind map, administrators will be able to demonstrate the true value in their programs, thereby helping to ensure that they will continue providing a positive impact on youth development in the future.

\section{References}

Bocarro, J., Greenwood, P.B., \& Henderson, K.A. (2008). An integrative review of youth development research in selected United States recreation journals. Journal of Park and Recreation Administration, 26(2), 4-24.

Caldwell, L.L., Younker, A.S., Wegner, L., Patrick, M.E., Vernani, T. Smith, E.A., \& Flisher, A.J. (2008). Understanding leisure-related program effects by using process data in HealthWise South Africa Project. Journal of Park and Recreation Administration, 26(2), 146-162.

Cresswell, J. W. (1998). Qualitative inquiry and research design: Choosing among five traditions. Thousand Oaks, CA: Sage.

DeGraaf, D.G., Jordan, D.J., \& DeGraaf, K.H. (1999). Programming for parks, recreation, and leisure services: A servant leadership approach. State College, PA: Venture.

Gilliam, W.S., \& Zigler, E F. (2000). A critical meta-analysis of all evaluations of state-funded preschool from 1977 to 1998: Implications for policy, service delivery and program evaluation. Early Childhood Research Quarterly, 15(4), 441-473.

Henderson, K.A., \& Bialeschki, M.D. (2002). Evaluating leisure services: Making enlightened decisions. State College, PA: Venture.

Search Institute. (2004). 40 developmental assets. Retrieved February 19, 2009, from: http://www.search-institute.org/assets/forty.html

Wells, M.S., \& Arthur-Banning, S.G. (2007). South Carolina Children Youth and Families At-Risk (CYFAR) year end report. U.S. Department of Agriculture.

Witt, P.A., \& Crompton, J.L. (1999). Youth recreation services: Embracing a new paradigm for the new millennium. Management Strategy, 23(4), 1-7.

(C) Copyright of Journal of Youth Development Bridging Research and Practice. Content may not be copied or emailed to multiple sites or posted to a listserv without copyright holder's express written permission. However, users may print, download or email articles for individual use. 